DEPARTAMENTO DE PATOLOGIA E CLFNICA MEDICAS (2,a cadeira)

Diretor: Prof. Dr. Romeu Diniz Lamounier

DEPARTAMENTO DE ZOOTECNIA GERAL, GENETICA ANIMAL E BROMATOLOGTA

Diretor: Prof. Dr. Milton de Souza Piza

\title{
O MÉTODO DE SAHLI NA DETERMINAÇÃO DA HEMOGLOBINA EM FRANGOS NEW-HAMPSHIRE
}

(THE SAHII METHOD TO FIND OUT THE HEMOGLOBIN CONTENT IN NEW-HAMPSHIRE CHICKENS)

\author{
Romeu Diniz Lamounier Paulo de Carvalho Pereira Fernando Andreasi \\ Assistente \\ Assistente
}

Não é raro que o médico veterinário necessite de exames de laboratório para orientação de seus casos clínicos; todavia, a inexistência de laboratórios especializados accessíveis torna, por vêzes, muito árduo o trabalho do clínico, que passa a ser obrigado, pessoalmente, a proceder alguns dêsses exames. Em tais casos limita-se, naturalmente, às verificações mais simples e que exigem técnica fácil, como é o caso da dosagem de hemoglobina no sangue pelo método de Sahli.

A dosagem de hemoglobina no sangue é índice importante para a clínica veterinária e sua determinação rápida pelo Sahli faz dêsse aparêlho valioso auxiliar do clínico; entretanto, é bem sabido que o aludido método apresenta, quase sempre, resultados cujos erros se colocam na ordem de $10 \%$, além de que o aparêlho deve ser aferido de quando em quando, tendo-se em vista, inclusive, a espécie animal com que se pretende trabalhar.

O desenvolvimento da cultura avícola entre nós vem acentuando o interêsse. do veterinário para êsse ramo da zootecnia, e nossa atenção foi levada para a 
dosagem da hemoglobina no sangue de frangos New-Hampshire em idade de consumo.

A determinação do teor de hemoglobina em frangos apresenta dificuldades inerentes ao próprio sangue do animal, como muito bem salienta BANKowsKI (1), - qual, trabalhando com seis métodos, nos mesmos animais, encontra as seguintes diferenças:

QUADRO I

Teor médio de hemoglobina do sangue de 101 pintos Leghorn, com 42 a 56 dias de idade, determinado por seis métodos (Bankowski)

\begin{tabular}{|c|c|c|c|c|c|c|}
\hline & \multirow{2}{*}{ Dare } & \multirow{2}{*}{$\begin{array}{l}\text { Haden- } \\
\text { Hauser }\end{array}$} & \multirow{2}{*}{$\begin{array}{l}\text { Newco- } \\
\text { mer mo- } \\
\text { dificado }\end{array}$} & \multirow{2}{*}{$\begin{array}{l}\text { Sheard- } \\
\text { Sanford }\end{array}$} & \multicolumn{2}{|c|}{ Fotoelétrico } \\
\hline & & & & & H. ácida & $\begin{array}{l}\text { H. alca- } \\
\text { lina }\end{array}$ \\
\hline $\begin{array}{r}\text { Média em g por } 100 \mathrm{~cm} 3 \\
\text { de sangue } \ldots \ldots \ldots \ldots\end{array}$ & 7,72 & 7,84 & 9,71 & 8,91 & 9,83 & 12,13 \\
\hline Desvio padrão (土) ... & 0,91 & 0,83 & 0,93 & 0,87 & 1,00 & 0,99 \\
\hline C.v.\% $\ldots \ldots \ldots \ldots \ldots$ & 11,79 & 10,59 & 9,58 & 9,76 & 10,17 & 8,16 \\
\hline
\end{tabular}

0 método de Sahli, bastante difundido em nosso meio, não consta, entretanto, dessas pesquisas, o que nos levou a empregá-lo para a verificação do teor médio de hemoglobina em frangos de idade aproximada à dos usados por BANKowski.

De início decidimos testar o nosso aparêlho - Hemômetro de Sahli-Adans, com planos paralelos, n.? A-2505 - usando a seguinte técnica:

Sangue oxalatado de galinha foi obtido em quantidade tal que nos permitiu fazer diluições exatas com o próprio plasma obtido por centrifugação. O concentrado de hemátias, rigorosamente dosado pelo método de Wong, citado por Kolmer $\left({ }^{2}\right)$, forneceu-nos a base para o cálculo das quantidades teóricas de hemoglobina que passaríamos a obter em tôdas as diluições e destas tirávamos material para dosagens de oxi-hemoglobina em Luminetron e no nosso aparêlho de Sahli. Os resultados obtidos estão tabelados no quadro seguinte: 
QUADRO II

Aferição do aparelho do Sahli pela dosagem da oxi-hemoglobina (valor inicial encontrado pelo Wong $=22,0 \mathrm{~g} \%$ de hemoglobina)

\begin{tabular}{c|c|c|c|c|c|c}
\hline \multicolumn{2}{c|}{ Diluiçōes } & $\begin{array}{c}\text { (A) } \\
\text { teórico } \\
\mathbf{g} \%\end{array}$ & $\begin{array}{c}\text { (B) } \\
\text { oxi-hemo- } \\
\text { globina } \\
\text { g\% }\end{array}$ & $\begin{array}{c}\text { (C) } \\
\text { Sahli } \\
\text { g\% \% }\end{array}$ & $\begin{array}{c}\text { Dif. entre } \\
\text { A e B \% }\end{array}$ & $\begin{array}{c}\text { Dif. entre } \\
\text { A e C \% }\end{array}$ \\
\hline \hline 1,0 & 0,0 & 22,0 & 22,2 & 24,4 & $+0,9$ & $+10,9$ \\
0,8 & 0,2 & 17,6 & 16,8 & 18,4 & $-4,5$ & $+4,5$ \\
0,7 & 0,3 & 15,4 & 14,8 & 16,4 & $-3,9$ & $+6,5$ \\
0,6 & 0,4 & 13,2 & 13,0 & 14,2 & $-1,5$ & $+7,6$ \\
0,5 & 0,5 & 11,0 & 11,3 & 12,2 & $+2,7$ & $+10,9$ \\
0,4 & 0,6 & 8,8 & 9,2 & 9,4 & $+4,5$ & $+6,8$ \\
0,3 & 0,7 & 6,6 & 6,4 & 7,0 & $-3,0$ & $+6,1$ \\
0,2 & 0,8 & 4,4 & 4,3 & 4,8 & $-2,3$ & $+9,1$ \\
\hline
\end{tabular}

Verifica-se assim que, en êrro médio de $-0,8 \%$ em relariono acs valores teóricos, o método de Sahli mostra um êrro médio de $+7,8 \%$.

Éstés resultados sugerem que o nosso aparêtho de Sahli comete um êrro sistemático, para mais, em se tratando de sangue de galinha, e que, portanto, poder-se-ia melhorar os resultados obtidos multiplicando-se por um fator de correção, cujo valor, para o nosso aparêlho, é igual a 0,93 .

De posse dêstes dados, fizemos algumas verificaçōes, usando 102 frangos da raça New-Hampshire, clinicamente normais, com cêrca de 2 e 3 meses de idade (58 a 60 e 88 a 90 dias, respectivamente), alimentados com ração adquirida no comércio e tida como balanceada.

A diferenciação dos sexos foi feita por caracteríslicos de crescimento da crista, barbela e penas da cauda.

O sangue foi colhido por picada da veia axilar, desprezando-se a primeira quantidade fluída.

Os resultados encontrados constam do quadro que se segue, onde apresentamos também, os valores corrigidos: 


\section{QUADRO III}

Hemoglobina em g por $100 \mathrm{~cm} 3$ de sangue

\begin{tabular}{|c|c|c|c|c|c|c|c|}
\hline Aves & $\operatorname{com} 58$ a & 60 dias 0 & idade & Aves & com $88 \quad a$ & 90 dias $d$ & idade \\
\hline $\mathrm{M}$ a & $c \mathbf{h} \quad \mathbf{o} s$ & F ê r & e a $s$ & $\mathrm{M}$ a & $h \cap s$ & $F$ è & e a $\mathbf{s}$ \\
\hline Achado & Corrigido & Achado & Corrigido & Achado & Corrigide & Achado & Corrigido \\
\hline $\begin{array}{r}8,0 \\
8,5 \\
9,0 \\
9,0 \\
9,2 \\
9,5 \\
10,0 \\
10,0 \\
9,5 \\
10,6 \\
10,8\end{array}$ & $\begin{array}{r}7,4 \\
7,9 \\
8,4 \\
8,4 \\
8,5 \\
8,8 \\
9,3 \\
9,3 \\
8,8 \\
9,8 \\
10,0\end{array}$ & $\begin{array}{r}7,8 \\
8,0 \\
8,0 \\
8,2 \\
8,5 \\
8,6 \\
9,0 \\
9,0 \\
9,0 \\
9,0 \\
9,0 \\
9,2 \\
9,4 \\
9,5 \\
9,6 \\
10,0 \\
10,0 \\
10,0 \\
11,0 \\
7,8 \\
8,6 \\
9,5 \\
10,5 \\
10,6 \\
11,2 \\
\end{array}$ & $\begin{array}{r}7,2 \\
7,4 \\
7,4 \\
7,6 \\
7,9 \\
8,0 \\
8,4 \\
8,4 \\
8,4 \\
8,4 \\
8,4 \\
8,5 \\
8,7 \\
8,8 \\
8,9 \\
9,3 \\
9,3 \\
9,3 \\
10,2 \\
7,2 \\
8,0 \\
8,8 \\
9,8 \\
9,8 \\
10,4 \\
\end{array}$ & $\begin{array}{r}10,0 \\
10,0 \\
10,8 \\
11,0 \\
11,0 \\
11,0 \\
11,2 \\
11,8 \\
12,0 \\
12,4 \\
12,6 \\
13,0 \\
8,4 \\
8,8 \\
9,5 \\
9,5 \\
10,0 \\
10,2 \\
10,4 \\
11,0 \\
11,4 \\
11,6 \\
11,8 \\
10,6 \\
11,0 \\
11,5\end{array}$ & $\begin{array}{r}9,3 \\
9,3 \\
10,0 \\
10,2 \\
10,2 \\
10,2 \\
10,4 \\
11,0 \\
11,2 \\
11,5 \\
11,7 \\
12,1 \\
7,8 \\
8,2 \\
9,8 \\
8,8 \\
9,3 \\
9,5 \\
9,7 \\
10,2 \\
10,6 \\
108 \\
11,0 \\
9,8 \\
10,2 \\
10,7\end{array}$ & $\begin{array}{r}8,2 \\
8,5 \\
8,5 \\
8,6 \\
9,2 \\
9,4 \\
9,5 \\
9,5 \\
9,8 \\
10,0 \\
10,0 \\
10,0 \\
10,2 \\
10,2 \\
10,2 \\
10,2 \\
10,5 \\
10,5 \\
10,6 \\
10,6 \\
10,8 \\
10,8 \\
11,0 \\
11,2 \\
11,5 \\
11,5 \\
12,6 \\
13,4 \\
8,0 \\
10,0 \\
10,2 \\
10,4 \\
10,5 \\
11,0 \\
11,0 \\
12,4 \\
8,8 \\
11,2 \\
12,0 \\
12,4\end{array}$ & $\begin{array}{r}7,6 \\
7,9 \\
7,9 \\
8,0 \\
8,5 \\
8,7 \\
8,8 \\
8,8 \\
9,1 \\
9,3 \\
9,3 \\
9,3 \\
9,5 \\
9,5 \\
9,5 \\
9,5 \\
9,8 \\
9,8 \\
9,8 \\
9,8 \\
10,0 \\
10,0 \\
10,2 \\
10,4 \\
10,7 \\
10,7 \\
11,7 \\
12,5 \\
7,4 \\
9,3 \\
9,5 \\
10,7 \\
11,2 \\
11,5\end{array}$ \\
\hline & $\bar{x}=8,8$ & & $\bar{x}=8,6$ & & $\bar{x}=10,1$ & & $\overline{\mathrm{x}}=9,6$ \\
\hline \multicolumn{2}{|c|}{$n=11$} & \multicolumn{2}{|c|}{$\mathbf{n}=25$} & \multicolumn{2}{|c|}{$\mathbf{n}=26$} & \multicolumn{2}{|c|}{$n=40$} \\
\hline
\end{tabular}




\section{INTERPRETAÇÃO ESTATISTICA}

A análise estatística dos resultados evidencia o seguinte:

\section{QUADRO IV}

Hemoglobina em g por $100 \mathrm{~cm} 3$ de sangue

Machos e fêmeas - พMade: 58 a 60 dias

\begin{tabular}{|c|c|c|c|c|c|}
\hline S e $\mathbf{x} 0$ & $\bar{x}$ & $\mathbf{S}+$ & $\overline{S x} \pm$ & C.V. \% & $\mathbf{n}$ \\
\hline Machos ......... & 8,8 & 0,8 & 0,2 & 8,3 & 11 \\
\hline Fêmeas $\ldots \ldots \ldots$ & 8,6 & 0,9 & 0,2 & 10,5 & 25 \\
\hline
\end{tabular}

0 teste $t$, aplicado aos teores médios constantes do quadro IV revelou-se igual a 0,7 , não significativo ao nível de $5 \%$, denunciando que as diferenças assilıaladas não devem ser imputadas ao sexo dos indivíduos, mas sim atribuíveis as acaso.

\section{QUADRO V}

Hemoglobina em $\mathrm{g}$ por $100 \mathrm{~cm} 3$ de sangue

Machos e fêmeas - Idade: 88 a 90 dias

\begin{tabular}{c|c|c|c|c|c}
\hline \multicolumn{1}{c|}{$\mathbf{S}$ e $\mathbf{x} \circ$} & $\overline{\mathbf{x}}$ & $\mathbf{S}+\ldots$ & $\mathbf{S x} \pm$ & C.V. \% & $\mathbf{n}$ \\
\hline \hline Machos $\ldots \ldots \ldots \ldots$ & 10,1 & 1,0 & 0,2 & 10,31 & 26 \\
Fêmeas $\ldots \ldots \ldots \ldots$ & 9,6 & 1,1 & 0,2 & 11,4 & 40 \\
\hline
\end{tabular}

Comparando os valores médios obtidos, de um lado os dos machos, e de outro os das fêmeas, pela aplicação do teste $t$, obtivemos o resultado igual a 1,9 , não significativo, mesmo ao nível de $5 \%$, o que nos indica não haver, entre os sexos, diferenças nos teores de hernoglobina, estatisticamente significantes.

Diante dêstes resultados, reunimos, de um lado, os valores relativos às aves de três meses, independentemente dos sexos, e de outro, tôdas as aves de dois meses de idade.

Com êste critério visamos verificar se as diferenças entre as médias das aves de idades diversas são estatìsticamente significativas. 
Os resultados são vistos no quadro VI.

\section{QUADRO VI}

Hemoglobina em g por $100 \mathrm{~cm} 3$ de sangue

Machos e fêmeas reunidos

\begin{tabular}{c|c|c|c|c|c}
\hline I. d a d e & $\bar{x}$ & $S_{ \pm}$ & $\overline{S x} \pm$ & C.V.\% & $n$ \\
\hline 58 a 60 dias $\ldots \ldots$ & 8,6 & 0,9 & 0,1 & 10,0 & 36 \\
88 a 90 dias $\ldots \ldots$ & 9,8 & 1,1 & 0,1 & 11,4 & 36 \\
\hline
\end{tabular}

Confrontando-se os teores médios constantes do quadro VI, encontramos o seguinte valor resultante da aplicação do teste $t: 6,0$, significativo, ao nível de $1 \%$.

Concluímos, portanto, que embora não houvesse diferenças significativas entre os sexos para aves da mesma idade, o teste $t$, quando aplicado aos valores médios relativos às aves de idades diferentes, revelou-se altamente significativo.

Não podemos pretender que êstes resultados expressem o valor real da hemoglohina normal em sangue de frango New-Hampshire de 2 e 3 meses dc idade, principalmente porque a ração do comércio utilizada na dieta não foi testada, embora tivesse a indicação de que era balanceada. Contudo, os nossos resultados, pelo emprêgo do método de Sahli, acusam valores bem próximos dos obtidos por BankowsKi, para animais da mesma idade e de raça Leghorn, usando os miétodos de Newcomer modificado, de Sheard-Sanford e da hematina ácida.

\section{RESUMO}

Os AA., considerando o uso do hemoglobinômetro de Sahli no exercício da clínica veterinária, sugerem a conveniência de se aferir êsse aparêlho em relação à espécie animal para a qual vai ser usado. Explicam como se pode fazer uma aferição rápida, por intermédio de diluições de um sangue cuja hemoglobina foi determinada por um método mais exato e apresentam os resultados de 102 verificações em frangos de 2 e 3 meses de idade, da raça New-Hampshire. 


\section{SUMMARY}

The applicability of the hemoglobinometre of Sahli in the clinical veterinary field has been considered by testing the hemoglobinometre of Sahli according to the animal species of which blood must be investigated. This, can be done quickly from blood dilutions of which hemoglobin had been determined by a more exact method. The results obtained with the blood of 102 New-Hampshire chickens, two and three months of age, have been reported.

\section{BIBLIOGRAFIA}

1 - Bankowski, R. A. - 1942 - Studies of the hemoglobin content of chicken blood and evaluation of method for its determination. Am. Jour. Vet. Res., 3:373-81

2 - Kolmer, J. A. - Boerner, F. - 1939 - Técnica de laboratório: 814-5. Trad 2.* ed. americana. Rio de Janeiro, Editora Guanabara 